\title{
EVALUATION OF WINDOW GLASSES TRANSMISSION AND SUNLIGHT GUIDING SYSTEM IN A SOLAR-BASED VERTICAL GREENHOUSE
}

\begin{tabular}{|c|c|}
\hline & tie Zha \\
\hline $\begin{array}{r}{ }^{1} \text { School of Power an } \\
{ }^{2} \text { Fotil } \\
\text { School of Mechanical an } \\
\text { https://doi.org/10.343 } \\
\end{array}$ & $\begin{array}{l}\text { al Engineering, Wuhan University, Wuhan 430063, Hubei, China. } \\
\text { tare Germany GmbH, } 40547 \text { Düsseldorf, Germany. } \\
\text { e Engineering, Nanyang Technological University, Singapore 639798, } \\
\quad \text { Singapore. } \\
\quad \begin{array}{l}\text { MYNG@ntu.edu.sg } \\
\text { 2021.13.1.1 }\end{array}\end{array}$ \\
\hline $\begin{array}{l}\text { Article history: } \\
\text { Received: } \\
\quad 28 \text { September } 2020 \\
\text { Accepted: } \\
\quad 25 \text { February } 2021 \\
\end{array}$ & $\begin{array}{l}\text { ABSTRACT } \\
\text { Vertical farming is believed to be a solution to the potential global food } \\
\text { shortage in the future. However, it also receives many doubts about using } \\
\text { excessive energy to support its artificial lighting system. In this paper, a } \\
\text { solar-based vertical greenhouse is investigated based on a baseline }\end{array}$ \\
\hline $\begin{array}{l}\text { Keywords: } \\
\text { Greenhouse; } \\
\text { Vertical farming; } \\
\text { Ray tracing; } \\
\text { Sunlight guiding system; } \\
\text { Window glasses transmission }\end{array}$ & $\begin{array}{l}\text { greenhouse configuration. Ray tracing method is utilized to simulate the } \\
\text { solar energy delivered to crop surfaces through window glasses transmission } \\
\text { and artificially from a sunlight guiding system. Simulated results } \\
\text { demonstrated that elevating the floor height and introducing a sunlight } \\
\text { guiding system can improve the sunlight amount without using artificial } \\
\text { lighting. }\end{array}$ \\
\hline
\end{tabular}

\section{Introduction}

On the global level, urbanization has been accelerated by population growth in the past decades. Unprecedentedly, over half of the world's population lives in urban areas. According to the UN's Dept. of Economic and Social Affairs prediction, the world`s population will surpass the 9 billion mark by 2050 (United_Nations, 2004). This trend has threatened the production, processing, and delivery of food. Sustainable solutions are expected to supply fresh, local food for the urban population. Researchers believe that closed production systems in cities can be the cure, namely plant factories, vertical farms and rooftop greenhouses (Kozai, Ohyama, \& Chun, 2006). Vertical Farming (VF) is attracting public attention because it can achieve remarkable food production with very limited land area usage. Skyscrapers are equipped with artificial lighting infrastructure, environmental adjusting facilities, nutritional controlling appliances to realize fast growth and high yield of crops
(Beacham, Vickers, \& Monaghan, 2019; Ng \& Foo, 2020; Kozai, 2013; Specht et al., 2013). Nevertheless, although these sorts of equipment benefit the production rate, they also bring problems to the system. One critical problem of $\mathrm{VF}$ is that it needs large energy consumption, especially on the artificial lighting system (Germany_Aerospace_Center, 2012). According to a feasible study of vertical farm conducted by Germany Aerospace Center, to construct a 37-floor vertical farm building will cost 139,454 Euros, however, the total cost of above-mentioned equipment for this building is 145,215 Euros, even higher than the building itself, $59 \%$ of these special expenses are utilized on lighting equipment such as LED panels and heat exchanger systems to cool down the LEDs. Besides, in daily usage, the artificial lighting system also requires $20 \%$ of the total energy consumption, contributes to the second-biggest consumer of electric power in operating a VF. Reducing the dependence on artificial light is 
significant to push VF towards large-scale applications. In this context, guiding more sunlight might be a promising solution to cut energy consumption.

Generally, windows and sunlight guiding system are two paths for daylight transmission into a VF. The purpose of this research, therefore, is to evaluate these two methods and their effects of guiding daylight into vertical farms based on a comparison study to a baseline greenhouse.

\section{Material and methods}

The typical agriculture building utilizing the maximum of solar energy is the greenhouse. In the urban areas, the rooftop greenhouse is also a solution to the food production problem (Specht et al., 2013). To study how the sunlight enters the indoor area, a single floor rooftop greenhouse is built as a baseline as shown in Fig. 1. Total solar energy during the shortest day of the year is evaluated and recorded, the date and place are 22nd December in Singapore. Then, vertical multi-floor greenhouses are designed to evaluate whether each floor can still absorb enough sunlight for crop cultivation. Two different floor heights are set to evaluate the amount of window glasses transmission, the normal floor height is 3 meter and an elevated height is 6 meter, results are compared to evaluation whether elevating the height can effectively improve the sunlight amount. Additionally, a sunlight guiding system is built to study the amount of solar energy introduced by sunlight collectors (Ullah \& Shin, 2014; Yalçın \& Ertürk, 2020) though the fully glazed greenhouse may not need a sunlight guide system during the sunny day. Results are compared to window transmission. Note that crop growth depends on PAR illumination and plants might also get stressed under high PAR illumination reducing the crop growth. Thus, ensuring growth everyday does not necessarily ensures maximum crop growth.

\subsection{Modeling of greenhouses and vertical greenhouses}

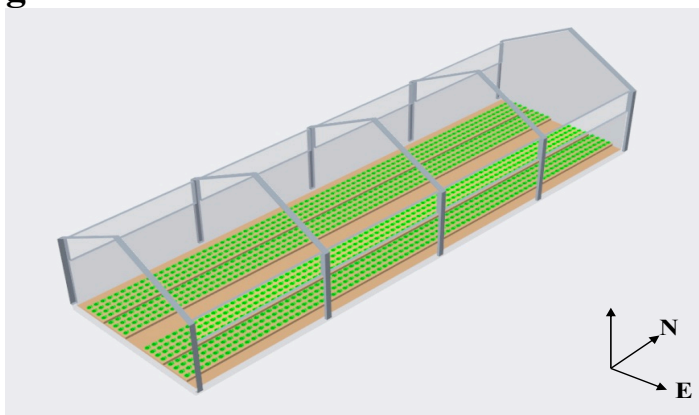

(a)

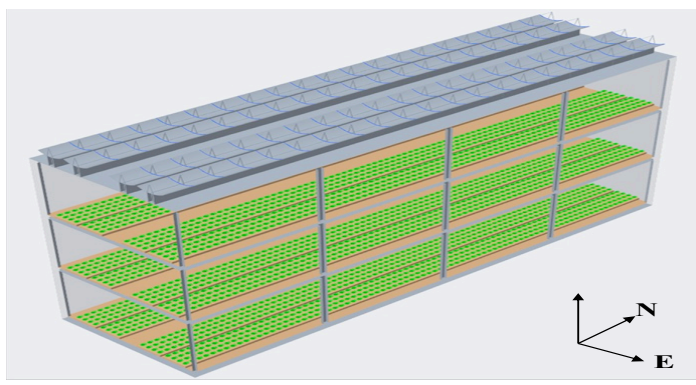

(b)

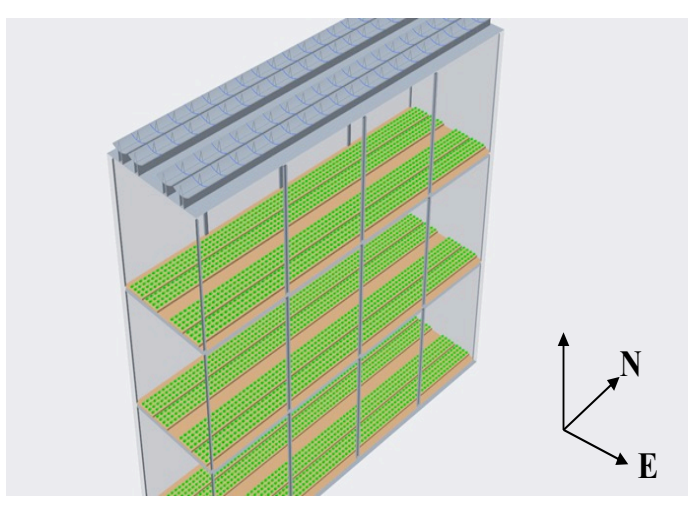

(c)

Figure 1. Layouts of the: (a) baseline greenhouse, (b) vertical multi-floor greenhouse and (c) vertical greenhouse heightened (elevated floor height)

Fig. 1 (a) exhibits the layout of a rooftop baseline greenhouse. All the walls are built by glasses so that sunlight can easily reach the crop surfaces. The rooftop position ensures the ideal location with no shade and shadow from other buildings in cities. Thus, results based on this model will be the baseline for the upcoming evaluations. 
Figs. 1 (b) and (c) show the structure of two three-floor vertical greenhouses with a floor height of 3 meters and 6 meters, respectively. Since cost estimate from references has demonstrated that VF building is more affordable than its equipment, (Germany_Aerospace_Center, 2012) the 6- meter solution will be considered and assumed as an affordable scenario, which is supposed to add less cost than a sunlight guiding system. For these three buildings, two larger façades are placed toward east and west to absorb more sunlight energy. Layout parameters are listed in Table 1.

Table 1. Layouts of the baseline greenhouse, vertical greenhouse and vertical greenhouse heightened

\begin{tabular}{|c|c|c|c|c|c|c|}
\hline $\begin{array}{c}\text { Name of } \\
\text { building }\end{array}$ & $\begin{array}{c}\text { Length } \\
{[\mathrm{m}]}\end{array}$ & $\begin{array}{c}\text { Width } \\
{[\mathrm{m}]}\end{array}$ & $\begin{array}{c}\text { Floor } \\
\text { height } \\
{[\mathrm{m}]}\end{array}$ & $\begin{array}{c}\text { Number } \\
\text { of } \\
\text { floors }\end{array}$ & $\begin{array}{c}\text { Crops } \\
\text { Area } \\
\left(\mathrm{m}^{2}\right)\end{array}$ & $\begin{array}{c}\text { Collectors } \\
\text { Area }\left(\mathrm{m}^{2}\right)\end{array}$ \\
\hline $\begin{array}{c}\text { Baseline } \\
\text { Greenhouse }\end{array}$ & 20.2 & 6 & 3 & 1 & 80 & 0 \\
\hline $\begin{array}{c}\text { Vertical } \\
\text { Greenhouse }\end{array}$ & 20.2 & 6 & 3 & 3 & 240 & 80 \\
\hline $\begin{array}{c}\text { Vertical } \\
\text { Greenhouse } \\
\text { Heightened }\end{array}$ & 20.2 & 6 & 6 & 3 & 240 & 80 \\
\hline
\end{tabular}

\subsection{Modeling of sunlight guiding system}

The sunlight guiding system is supposed to collect abundant sunlight on the building roof, and then transfer the energy into indoor areas as a supplemental approach. To achieve a high concentration of sunlight, a parabolic trough is designed as shown in Fig. 2(a). Aluminum foil coated on the surface can help to realize the sunlight reflect rate of $95 \%$ (Venegas-Reyes, Jaramillo, Castrejón-García, Aguilar, \& SosaMontemayor, 2012).

The rectangular aperture height and the rectangular aperture width are both set as 1000 $\mathrm{mm}$ so that the vertical projection area is $1 \mathrm{~m}^{2}$. The parabolic trough in the middle and the convex parabolic reflector on the top match one another to ensure that the sunlight collected by the parabolic trough can be guided into the optic fibers inlet in the bottom, as shown in Fig. 2(a). The optical fibers inlets are in a linear array so that they can receive the maximum solar energy and transfer it to the crops. The proper arrange of reflectors to collimate the sunlight is designed by:

$$
F_{1}=F_{2}
$$

In this equation, $F_{1}$ and $F_{2}$ represent the focal point of the parabolic trough and the concave reflector, respectively. For the parabolic trough, the focal length is set to be $440 \mathrm{~mm}$. Every light to the inlet surface of the optical fibers is defined by

$$
H_{P R}=W_{r}
$$

The $H_{P R}$ represents the rectangular aperture height of the parabolic reflector and $W_{r}$ means the width of the receiver of optic fiber inlet. In this case, $W_{r}$ is $20 \mathrm{~mm}$ (Roland Winston, 2004).The sunlight captured by one collector will be transfer to $1 \mathrm{~m}^{2}$ crop area on each floor as shown in Fig 2(b). A Biconcave lens is introduced at the end of each bundle of optic fibers to diffuse the sunlight and to achieve a uniform distribution on crop surface. The transfer efficiency is set to be $60 \%$ according to literature (Liang, Monteiro, Teixeira, Monteiro, $\&$ Collares-Pereira, 1998). 


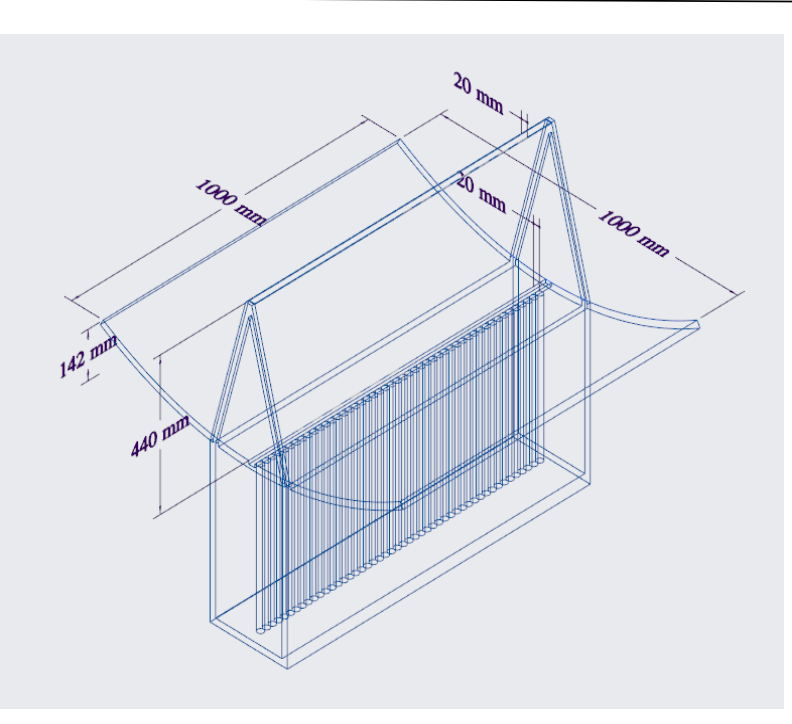

(a)

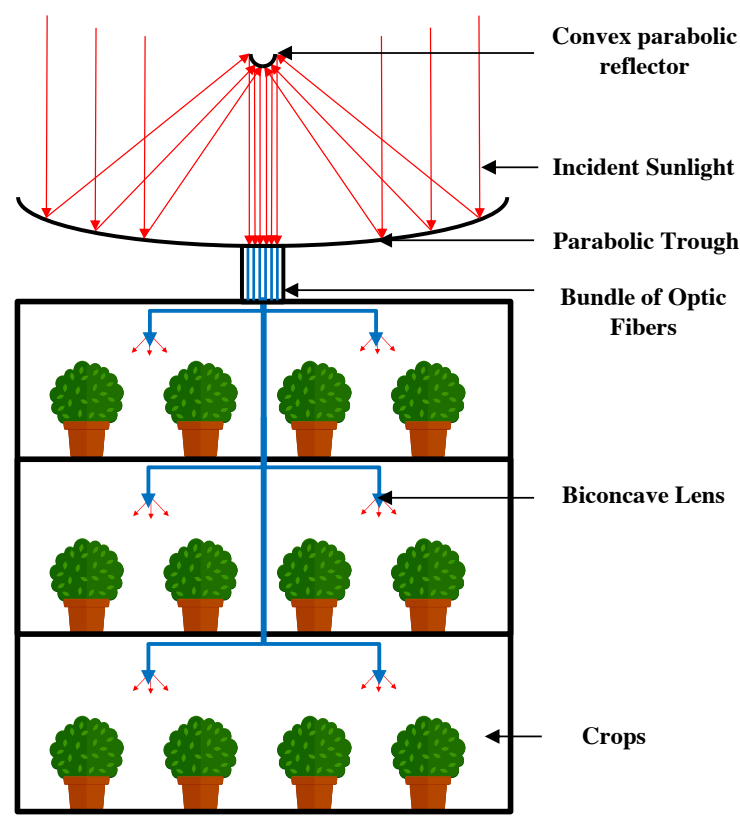

(b)

Figure 2. Layouts of (a) a single sunlight collector with projected area of $1 \mathrm{~m}^{2 ;}(\mathrm{b})$ Sunlight guiding system

\subsection{Solar load method}

To calculate the solar energy, the ray tracing method and solar load method is introduced.

The Theoretical Maximum Method is applied using ANSYS Fluent. The equation for direct normal irradiation is introduced based on NREL (National Renewable Energy Laboratory)'s Solar Position and Intensity Code (Solpos):

$$
E d n=S_{\text {etrn }} S_{\text {unprime }}
$$

The $S_{\text {etrn }}$ represents the direct normal solar irradiance from the top of the atmosphere. $S_{\text {unprime }}$ represents the correction number which can account for factors reducing solar load through the atmosphere.

The evaluation of the diffuse load in this solar model is calculated by methods from the 2001 ASHRAE Fundamental Handbook (ASHRAE, 2001). On a vertical surface, the definition for diffuse solar irradiation is represented as:

$$
E d=C Y E d n
$$

In which the $C$ represents a constant according to Tab. 7 from Chapter 30 of the 2001 ASHRAE Handbook of Fundamentals, $Y$ is the ratio of sky diffuse radiation on a vertical surface to that on a horizontal surface, which is count as a function of incident angle). Edn means the direct normal irradiation on a clear day.

Besides the vertical surfaces, diffuse solar irradiation for other surfaces is defined as:

$$
E d=C E d n \frac{(1+\cos \varepsilon)}{2}
$$

The tilt angle of the surface from the horizontal plane is defined as $\varepsilon$ in this equation represents.

For coated glazing, spectral transmissivity and reflectivity (assume gray approximation with no dependence on wavelength) are computed based on the normal angle of incidence (Elizabeth $U$ Finlayson, 1993).

Transmissivity is defined as:

$$
T(\theta, \lambda)=T(0, \lambda) \operatorname{Tref}(\theta, \lambda)
$$


In which:

$$
\begin{aligned}
& \operatorname{Tref}(\theta)=a 0+a 1 \cos (\theta)+a 2 \cos \left(\theta^{2}\right)+ \\
& a 3 \cos \left(\theta^{3}\right)+a 4 \cos \left(\theta^{4}\right)
\end{aligned}
$$

Reflectivity is defined as:

$$
R(\theta, \lambda)=R(0, \lambda)[1-\operatorname{Rref}(\theta)]+\operatorname{Rref}(\theta)
$$

In which:

$$
\begin{aligned}
& \operatorname{Rref}(\theta)=b 0+b 1 \cos (\theta)+b 2 \cos \left(\theta^{2}\right)+ \\
& b 3 \cos \left(\theta^{3}\right)+b 4 \cos \left(\theta^{4}\right)-\operatorname{Tref}(\theta)
\end{aligned}
$$

The normal transmissivity and reflectivity are defined as 0.8 and 0.1 respectively for the window glasses both in the greenhouse and vertical farms (Farkas et al., 2001; Graamans, Baeza, van den Dobbelsteen, Tsafaras, \& Stanghellini, 2018).

\section{Result and discussion}

\subsection{Grid independence result}

Three meshes with different elements number are built for each building. The solar heat flux on the unshaded top surfaces is recorded and converted into Daily Light Integral (DLI) value. Experiment results from literature carried out in Singapore are introduced to validate the simulation (Song, Tan, \& Tan, 2018).

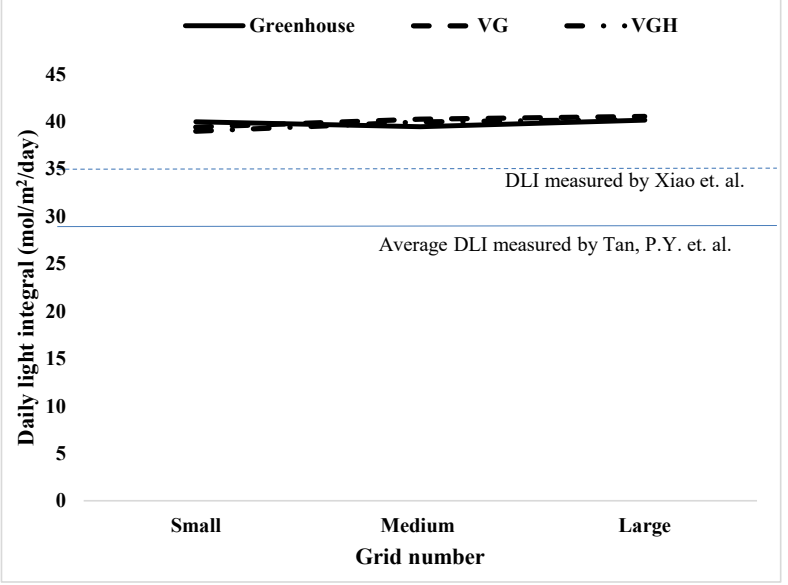

Figure 3. Grid independence result on layouts for baseline greenhouse, $\mathrm{VG}, \mathrm{VGH}$.
The grid independence results with ray tracing approach (ANSYS Fluent) in Fig. 3 shows that the increase in grid number from coarse, fine to finer does not obviously affect the DLI result. The values of daily maximum solar flux are converted to photosynthetically active radiation (PAR) based on a coefficient of 2.1 with reference to literature. (Robert W. Langhans, 1997) Calculated values of unshaded DLI are around $40 \mathrm{~mol} / \mathrm{m}^{2} /$ day, which is slightly higher than values from the measurement. This is possible because the measurement can take the shade of cloudy weather, atmosphere thickness, and shadow from other buildings into account, whereas simulations in this study are aimed to evaluate the ideal situation which does not consider these factors.

\subsection{Comparison of solar energy for different solutions.}

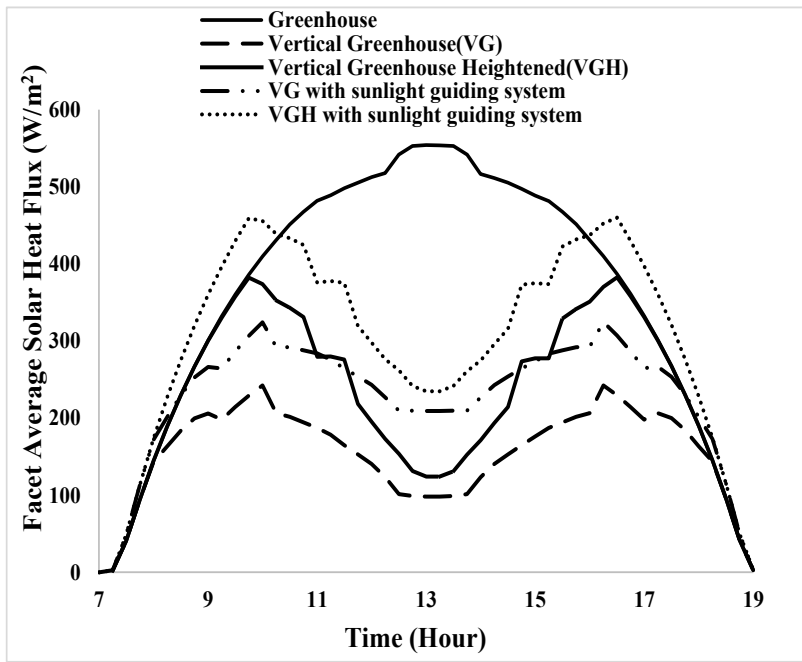

Figure 4. Solar energy during the day

Fig. 4 exhibits the simulation results of facet average solar heat flux. It can be observed that before 8:00 and after 18:00, the solar energy results in the greenhouse and vertical greenhouse are the same. This is because the solar zenith angles are low so the sunlight can enter the indoor area with no difference. However, when the solar zenith angle is high in the middle hours of the day, indoor areas of a multi-floor building cannot receive as much 
solar energy as the baseline greenhouse can. The sunlight collectors contribute more obviously to introduce additional sunlight energy.

\subsection{Comparison of DLI in different solutions.}

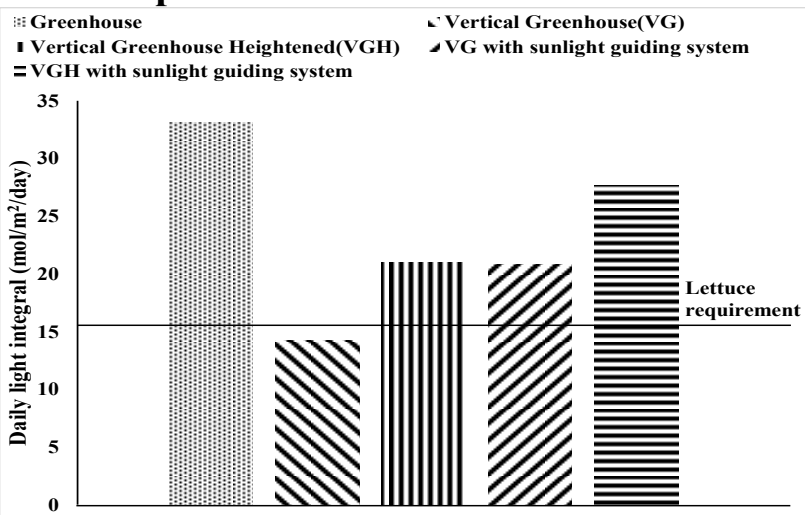

Figure 5. Comparison of DLI results for different layout solutions

Fig. 5 shows the DLI result of different layout solutions. The baseline greenhouse receives a DLI of $33.12 \mathrm{~mol} / \mathrm{m}^{2} /$ day. Compared to the unshaded value without glass walls of DLI around $40 \mathrm{~mol} / \mathrm{m}^{2} /$ day in the grid independence test, the lower DLI inside the greenhouse is caused by the reflection and absorption effect of the glass walls. However, this value can meet the requirement of various crops as presented in Table 2. The 3-meter vertical greenhouse receives an average DLI of only 14.23 $\mathrm{mol} / \mathrm{m}^{2} /$ day, which cannot meet the lettuce`s DLI requirement of 17 . Elevate the floor height or introduce the sunlight by the collector can increase the DLI up to 21.01 and 20.85, respectively. Implement both floor heightened and sunlight collector methods simultaneously can raise the DLI value to 37.32 , which is even higher than that of the baseline greenhouse.

Table 2. Crops requirements of DLI from reference

\begin{tabular}{|l|l|l|}
\hline Crops & $\begin{array}{l}\text { DLI requirement } \\
\left(\mathrm{mol} / \mathrm{m}^{2} / \text { day) }\right.\end{array}$ & Reference source \\
\hline Lettuce & $12-17$ & $\begin{array}{l}\text { (Song et al., 2018) } \\
\text { (NASA, 2018) }\end{array}$ \\
\hline Tomato & $27-30$ & $\begin{array}{l}\text { (Song et al., 2018) } \\
\text { (NASA, 2018) }\end{array}$ \\
\hline Onion & 17 & (NASA, 2018) \\
\hline Rice & 33 & (NASA, 2018) \\
\hline Cucumber & $5.5-30$ & (Song et al., 2018) \\
\hline
\end{tabular}

\subsection{Effects of elevating the floor height}

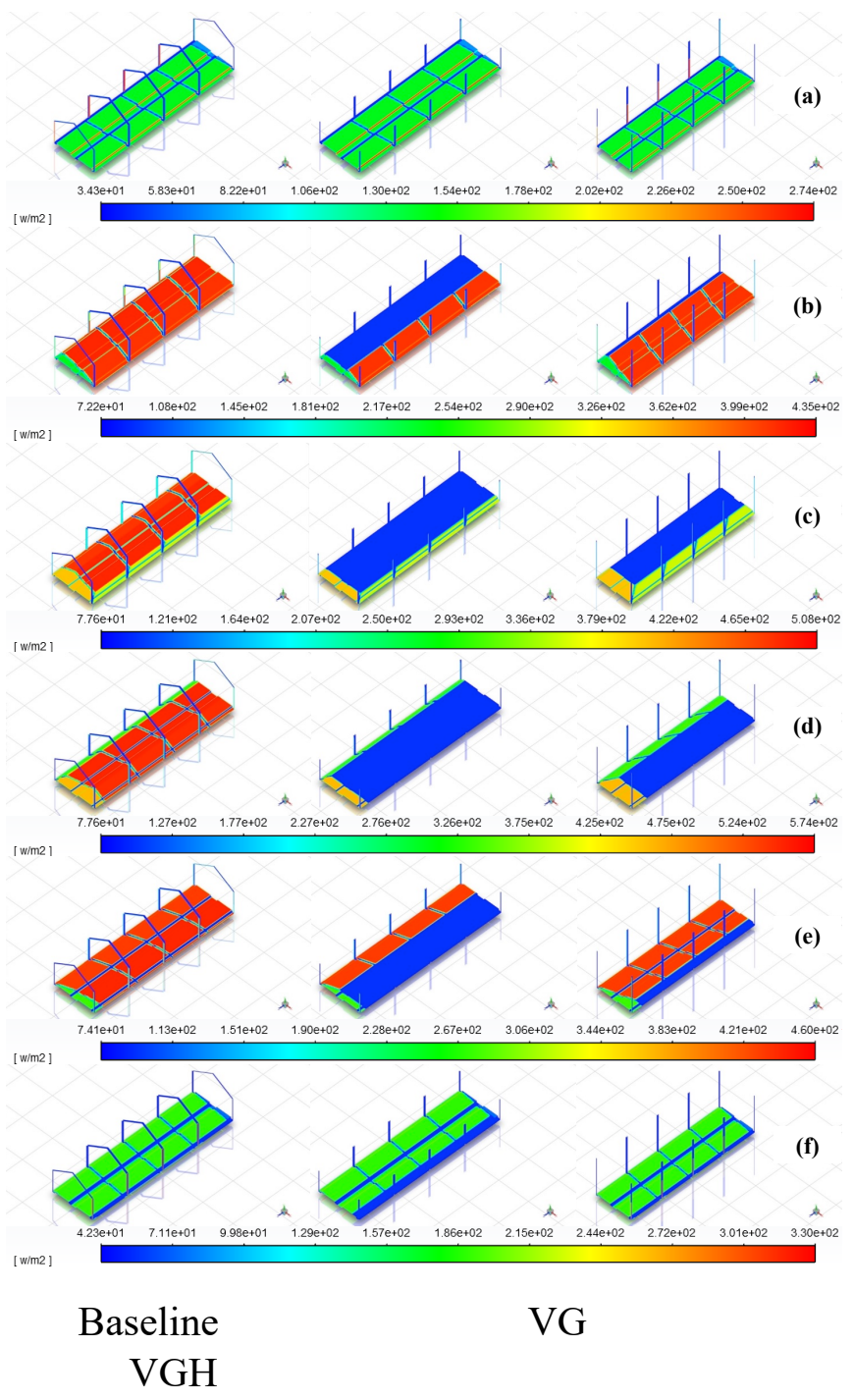

Figure 6. Solar heat flux distribution at different time during the day (a) 8:00, (b) 10:00, (c) 12:00, (d) 14:00, (e) 16:00, (f) 18:00

Fig. 6 shows the solar heat flux distribution at different hours during the day. It helps to explain the improvement caused by elevating the floor height. When the solar zenith angle is not high at times such as 10:00 and 16:00 as shown in Figs. 6 (b) (e), heightened floor allows more sunlight to pass the glass wall to enter the building. Crops can, therefore, extend the sunlight duration and grow better. 


\subsection{Effect of the sunlight guiding system}

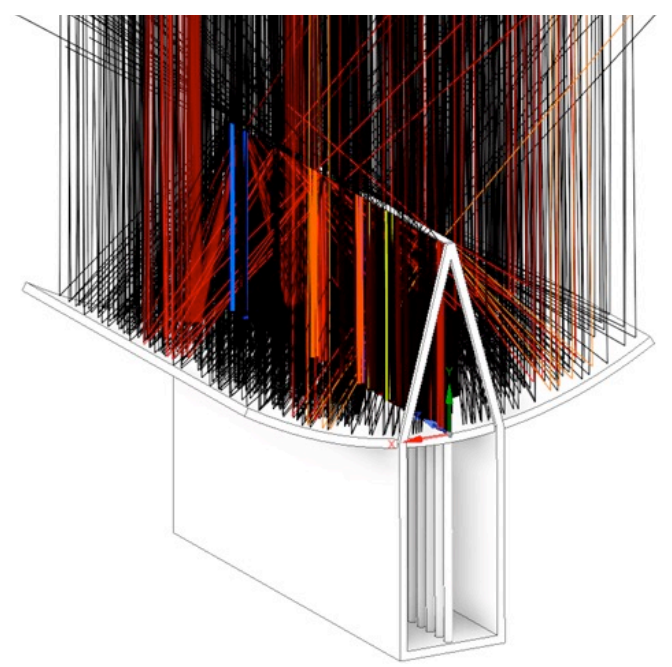

(a)

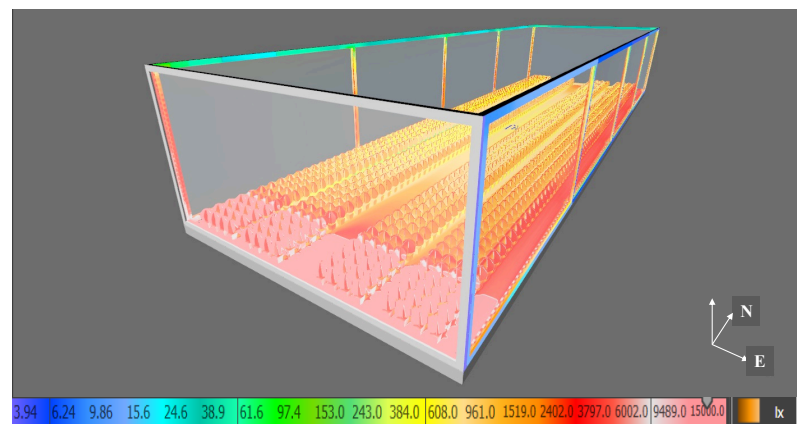

(b)

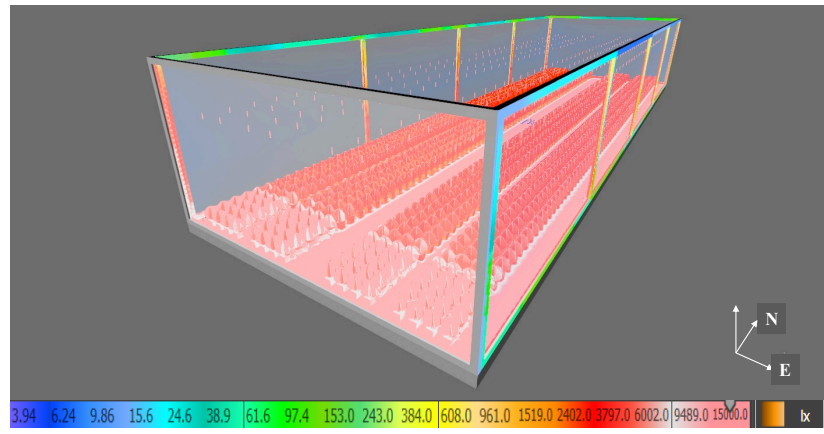

(c)

Figure 7. (a) Ray tracing of sunlight on the collector (b) Solar distribution on the vertical greenhouse without sunlight guiding system (c) Solar distribution on the vertical greenhouse with sunlight guiding system
Fig. 7 (a) visualized how the incident sunlight rays are collected and guided into the optical fibers. Figs. 7 (b) and (c) exhibit the lighting distribution of a vertical house with and without sunlight guiding system at 13:00 hour, it can be observed that with a dense array of diffuse lens, the sunlight collected by the system can be equality distributed on each of the crop surfaces and obviously elevated the illuminance on crop surfaces. In Fig. 7(c), a boundary can still be observed, dividing the area into the north part with an illuminance of about 3000 lux and the south part with an illuminance over 10000 lux, which means compared to the sunlight from window, the sunlight from the guiding system is less abundant. Three reasons might contribute to this difference. Firstly, at collecting stage, the sunlight guiding system collects the sunlight on only one floor on the roof but distributes the rays to multiple floors under the roof. In present study, one collector with the projection area of 1 $\mathrm{m}^{2}$ can feeds three different $1 \mathrm{~m}^{2}$ crops areas on three floors, therefore it is a ratio of $1 / 3$ in area. It is reasonable to infer that when the crops floors increase, the energy guided from the roof will be further distributed and insufficient, this is probably the reason that the sunlight guiding system can only be a supplementary approach to the LEDs rather than working independently in many other solutions. In comparison, the window transmission naturally does not have this one-to-many problem. Considering that most building roof has the same area of each floors, it is necessary to increase the collecting area of this system for further optimization, for instance, to expand the roof of buildings or introduce façades to collect more solar energy (Tablada et al., 2017). Secondly, the different transmission efficiencies of sunlight guiding system and glass window are accountable for this variation. The sunlight guiding system is comprised of various components in collecting, transporting, and distributing stages, each of them has a loss rate. In the collecting stage, the 
rays reflect twice with a loss of $5 \%$ at each time. In the transporting stage, the optical fiber bundles have a transmittance of $87 \%$ at a length of $3 \mathrm{~m}$ and $72 \%$ at a length of $8 \mathrm{~m}$ (Kandilli \& Ulgen, 2009). In this study, even the lower design of vertical greenhouse has an overall height of $9 \mathrm{~m}$, this means the optical fiber will lose or absorb probably $28 \%$ of the energy when transporting the sunlight. In the distributing stage, lens efficiency will further decrease the sunlight energy carried to the crop surface, the overall efficiency of this study is 0.6. In comparison, the glass window has a transmissivity of 0.8 . How to expose the crops in a vertical farm to the maximum of sunlight in a less wastage way is a question to be answered for further optimization.

\section{Conclusions}

Both proposed solutions, increasing the floor height and implementing a sunlight guiding system, can introduce additional solar energy to elevate the DLI and therefore help crops grow better. Artificial-light-free solutions for growing lettuce can be achieved in these cases based on the simulations. Elevating the floor height is an economic choice because the spending on construction and maintaining of sunlight guiding system can be saved. Additionally, compared to three stage of sunlight collecting, transporting and distributing in the sunlight guiding system, the window transmission has only one stage, optimizing the window layout and improving the window transmissivity might be future solutions to introduce more sunlight and reduce the dependence on LEDs. The sunlight guiding system also has its own benefits. It can bring more flexibility and improved efficiency in using the land area, and the sunlight introduced can be more evenly organized. However, expanding the collecting area and improving the efficiency of the threestage system are necessary to cut down the usage of artificial light. For instance, façade integrating approaches has been studied to provide more choices in sunlight collecting (Tablada, Kosorić, Huang, Lau, \& Shabunko,
2020), fluorescence coatings are utilized to improve the sunlight distribution efficiency (Yalçın \& Ertürk, 2020). This study is thus far limited to a simulation study and our further study will focus on these optimization directions with validations to confirm the artificial-lightfree solutions for growing lettuce. The solar modelling of the sunlight collector could also be validated by experimental data monitored from a real or scaled greenhouse since this sunlight transmittance system could be very complicated where such a complex optical system will not be easily calculated using several simple algorithms.

\section{References}

ASHRAE. (2001). Handbook Fundamentals. USA.

Beacham, A. M., Vickers, L. H., \& Monaghan, J. M. (2019). Vertical farming: a summary of approaches to growing skywards. The Journal of Horticultural Science and Biotechnology, 94(3), 277-283.

doi: 10.1080/14620316.2019.1574214

Elizabeth U Finlayson, D. K. A., Charlie Huizenga, Michael D Rubin, M. Susan Reilly. (1993). Window 4.0: Documentation of Calculation Procedures.

Farkas, I., Weihs, P., Biró, A., Laube, W., Eitzinger, J., \& Wójcicki, A. (2001). Modelling of radiative PAR transfer in a tunnel greenhouse. Mathematics and Computers in Simulation, 56(4-5), 357-368. doi: 10.1016/s0378-4754(01)00307-x

Germany_Aerospace_Center.

(2012).

Feasibility Study: Vertical Farm EDEN.

Graamans, L., Baeza, E., van den Dobbelsteen, A., Tsafaras, I., \& Stanghellini, C. (2018). Plant factories versus greenhouses: Comparison of resource use efficiency. Agricultural Systems, 160, 31-43. doi: 10.1016/j.agsy.2017.11.003

Kandilli, C., \& Ulgen, K. (2009). Review and modelling the systems of transmission concentrated solar energy via optical fibres. Renewable and Sustainable Energy Reviews, 13(1), 67-84. doi: 10.1016/j.rser.2007.05.005 
Kozai, T. (2013). Sustainable Plant Factory: Closed Plant Production Systems with Artificial Light for High Resource Use Efficiencies and Quality Produce. Acta Horticulturae (1004), 27-40. doi: 10.17660/ActaHortic.2013.1004.2

Kozai, T., Ohyama, K., \& Chun, C. (2006). Commercialized Closed Systems with Artificial Lighting for Plant Production. Acta Horticulturae (711), 61-70. doi: 10.17660/ActaHortic.2006.711.5

Liang, D., Monteiro, L. F., Teixeira, M. R., Monteiro, M. L. F., \& Collares-Pereira, M. (1998). Fiber-optic solar energy transmission and concentration.

Ng EYK and Foo CK (2020). Study of Solar based Vertical Farming Systems with Raytraced daylighting analysis and visualizations, Carpathian Journal of Food Science and Technology. 12(4): pp. 21-30.

NASA. (2018). Life Support Baseline Values and Assumptions Document: NASA.

Robert W. Langhans, T. W. T. (1997). Plant Growth Chamber Handbook.

Roland Winston, J. M., Pablo Benitez,. (2004). Nonimaging Optics.

Song, X. P., Tan, H. T. W., \& Tan, P. Y. (2018). Assessment of light adequacy for vertical farming in a tropical city. Urban Forestry \& Urban Greening, 29, 49-57. doi: 10.1016/j.ufug.2017.11.004

Specht, K., Siebert, R., Hartmann, I., Freisinger, U. B., Sawicka, M., Werner, A., Thomaier S, Henckel D, Walk H, Dierich, A. (2013). Urban agriculture of the future: an overview of sustainability aspects of food production in and on buildings. Agriculture and Human Values, 31(1), 33-51. doi: 10.1007/s10460013-9448-4

Tablada, A., Chaplin, I., Huang, H., Kosoric, V., Lau, S. K., Yuan, C., \& Lau, S. (2017). Assessment of Solar and Farming Systems Integration on Tropical Building Facades. Paper presented at the Proceedings of SWC2017/SHC2017.
Tablada, A., Kosorić, V., Huang, H., Lau, S. S. Y., \& Shabunko, V. (2020). Architectural quality of the productive façades integrating photovoltaic and vertical farming systems: Survey among experts in Singapore. Frontiers of Architectural Research. doi: 10.1016/j.foar.2019.12.005

Ullah, I., \& Shin, S. (2014). Highly concentrated optical fiber-based daylighting systems for multi-floor office buildings. Energy and Buildings, 72, 246-261.

doi: 10.1016/j.enbuild.2013.12.031

United_Nations. (2004). World population to 2300. (Department of Economic and Social Affairs, Trans.): United Nations.

Venegas-Reyes, E., Jaramillo, O. A., CastrejónGarcía, R., Aguilar, J. O., \& SosaMontemayor, F. (2012). Design, construction, and testing of a parabolic trough solar concentrator for hot water and low enthalpy steam generation. Journal of Renewable and Sustainable Energy, 4(5). doi: 10.1063/1.4751461

Yalçın, R. A., \& Ertürk, H. (2020). Improving crop production in solar illuminated vertical farms using fluorescence coatings. Biosystems Engineering, 193, 25-36. doi: 10.1016/j.biosystemseng.2020.02.007

\section{Acknowledgments}

Thanks the Journal's editor and reviewers for the constructive reviews in imroving the paper. 